\title{
Que tipo de estado de bem-estar social é este?
}

\begin{tabular}{lr}
\hline $\begin{array}{l}\text { Dinamir Antônio Crestani } \\
\text { Celmar Oliveira }\end{array}$ & $\begin{array}{l}\text { Universidade Estadual do Rio Grande do Sul, Especialização } \\
\text { em Gestão Pública, Porto Alegre, RS, Brasil } \\
\text { E-mails: dinamir-crtani@smarh.rs.gov.br } \\
\text { celmaroliv@gmail.com }\end{array}$ \\
\hline
\end{tabular}

Recebido em: 11 jun. 2017. Revisado em: 1 nov. 2017 Aceito: 4 dez. 2017.

DOI: http://dx.doi.org/10.21674/2448-0479.42.299-319

\section{Resumo}

O presente trabalho examina as origens do Estado de Bem-Estar Social, contextualizando sua formação e consolidação como política pública de caráter de seguridade social. No desenvolvimento do tema, são analisadas as características do surgimento do Estado de Bem-Estar Social na sociedade brasileira, interpretando o momento histórico e as alterações nas legislações que objetivavam diminuir as mazelas e riscos provocados pelo mercado nos campos econômico e social. Identifica-se com qual destas tipologias o Estado brasileiro mais se aproxima. O objetivo, portanto, é analisar como este Estado tem se estruturado em sua gestão para implementar políticas públicas para enfrentar as exigências das demandas relacionadas com o exercício dos direitos sociais. $O$ tema foi desenvolvido a partir de pesquisa qualitativa e bibliográfica, utilizando-se de fontes de dados secundários. A pesquisa apresenta a posição de autores a respeito da concepção de um Estado de bem-estar social e do desenvolvimento de políticas sociais e suas estruturas. Conclui-se que o Estado brasileiro começa a deixar para trás o modelo conservador e corporativista, aproximando-se do tipo de Estado de BemEstar Social Democrata, apesar das fragilidades das instituições, do modelo político praticado e das opções econômicas adotadas.

Palavras-chave: Estado de Bem-Estar Social. Políticas Públicas. Gestão Pública.

\section{Abstract}

\section{What kind of welfare state is this?}

The present study examines the origins of the Welfare State, contextualizing its formation and consolidation as a public policy of social security character. In the development of the theme, the characteristics of the emergence of the Social Welfare State in Brazilian society are analyzed, interpreting the historical moment and the changes in the legislation that aimed to reduce the ills and risks caused by the market in the economic and social fields. It is identified with which of these typologies the Brazilian State is closest. The objective, therefore, is to analyze how this State has structured itself in its management to implement public policies to meet the demands of the demands related to the exercise of social rights. The theme was developed based on qualitative and bibliographical research, using secon- dary data sources. The research presents the position of authors regarding the conception of a 
welfare state and the development of social policies and their structures. It is concluded that the Brazilian State begins to leave behind the conservative and corporatist model, approaching the type of Social Welfare State, despite the weaknesses of the institutions, the political model practiced and the economic options adopted.

Keywords: Welfare State. Public Policy. Public Administration.

\section{Introdução}

A relação entre Estado, mercado e sociedade nem sempre traz benefícios e justiça para quem deve ser, ao final das contas, o beneficiário desse encontro, que é a sociedade como um todo. O movimento decorrente da atuação do mercado nas diversas áreas existentes na sociedade pode causar muitos desequilíbrios econômicos e sociais que acabam por criar uma pressão sobre determinados indivíduos e também sobre o próprio Estado, causando situações de desamparo e de falta de condições mínimas ou adequadas para determinadas classes sociais, criando dificuldades de manutenção da estrutura organizacional de suas vidas ou ainda, num nível mais evolutivo, dificultando o desenvolvimento de suas mais amplas capacidades.

O surgimento de problemas sociais, em qualquer grau, acaba sempre repercutindo e exigindo a atuação da administração pública. Estas dificuldades terão maior ou menor impacto no grau de exigências a ser apresentado para a administração pública solucionar, conforme o nível em que o governo se encontrar, em relação à oferta de políticas públicas de proteção social. $O$ amadurecimento na implantação de proteções sociais e o acesso mais efetivo aos programas governamentais, permitem opções de recursos quando as crises estiverem consolidadas, e podem ser a diferença para saídas rápidas e soluções consistentes.

\section{A proteção social no Estado de bem-estar social}

Para se iniciar, é relevante determinar a partir de que momento o Estado preocupou-se em criar mecanismos que pudessem estender uma proteção, econômica e social, para diminuir as necessidades que determinadas camadas da população enfrentavam. A análise precisa contemplar as mudanças que o poder público precisou enfrentar na busca de soluções para as novas questões sociais prejudiciais à sociedade. Compreender os fatos causadores dessas mudanças e necessidades sociais que fizeram o Estado agir de forma protetiva e identificar o processo histórico é o primeiro movimento para conhecer a concepção do chamado Estado de Bem-Estar Social.

As origens da proteção social: Uma questão inicial é determinar se as dificuldades econômicas e sociais apresentadas por certas camadas da sociedade devem receber a atenção do Estado. Os direitos sociais se justificam? As pessoas possuem necessidades ou aspirações e desejos? As respostas para estas questões estão na raiz da aceitação ou não do Estado de Bem-Estar Social e de suas políticas públicas. Identificar a origem da ideia de proteção social é o início para entender o Estado de Bem-Estar Social. 
$\mathrm{Na}$ Europa, no período medieval, a perda da terra pelos camponeses, diminuiu a capacidade de subsistência e fez surgir um número elevado de pessoas, os 'pobres', que vagavam pelos burgos em busca de caridade e ajuda. Em 1388, a Inglaterra criava uma lei direcionada aos pobres, que estabelecia que qualquer pessoa adulta em condições de trabalhar somente poderia receber ajuda das paróquias se trabalhasse em troca. Em 1576, regulamentava-se o fornecimento de matéria-prima para incentivar o trabalho dos mendigos. Em 1601, aprova-se a chamada Lei dos Pobres - Poors Law Act - que tinha o objetivo de estender assistência social aos mais pobres e sem condições adequadas de vida. A Igreja, através de suas paróquias comunitárias, administrava a ajuda às pessoas necessitadas, que era alcançada conforme uma determinada classificação das pessoas. Numa primeira classificação, a ajuda era estendida para pessoas impotentes, assim consideradas as pessoas velhas, doentes e deficientes. Num segundo grupo, encontravam-se as pessoas aptas ao trabalho, mas que não possuíam um lar. No terceiro grupo, achavam-se as pessoas avessas ao trabalho fabril e a estas havia previsão de punições corretivas. (LAVINAS; COBO, 2009, p. 08)

Até então, praticava-se uma assistência paternalista. Em 1834, alterou-se essa legislação e a assistência passou a ser pública. A assistência destinada ao terceiro grupo foi extinguida, influenciada pelo pensamento liberal da época que entendia que esse tipo de assistência era mera caridade e não estimularia a procura por trabalho, incentivando a mendicância. Essa nova lei exigia contrapartidas dos beneficiários, restringindo os critérios de acesso à assistência, direcionada então somente para doentes e incapacitados. Ela permitiu a formação de um mercado de trabalho competitivo associado à emergência de um proletariado móvel, desprotegido socialmente e obrigado a vender a baixo preço e em qualquer parte a sua força de trabalho (PEREIRA, 2008, p. 106). Criaram-se as condições para a construção de uma sociedade favorável ao desenvolvimento e consolidação de uma economia de mercado (POLANYI, 1980, p. 141). Esse pensamento inseria-se num julgamento moral da pobreza, estigmatizando os beneficiários. Programas sociais modernos ainda sofrem a influência deste pensamento.

Não havia pensamento preventivo de assistência aos necessitados. A atuação era sempre posterior aos fatos. Na metade do século XIX, este pensamento começou a mudar. Na Alemanha, criou-se a ideia de um seguro social, que exigia a participação compulsória de empregadores e de trabalhadores. A proteção previa o amparo em situações de inatividade, quando o trabalhador estivesse doente ou velho. Este benefício era extensivo aos familiares dos trabalhadores. O desenvolvimento da ideia de proteção tem base com a Lei do Seguro Saúde (1883) e a Lei do Seguro contra Acidentes de Trabalho (1884).

Posteriormente, surgiram também legislações de proteção previdenciária. Aspecto importante foi o surgimento de proteções sociais para os trabalhadores, afastando o pensamento assistencialista. $\mathrm{O}$ caso alemão é reconhecido como o primeiro tipo de política social através de um seguro. Foi um pensamento que acabou se difundindo para outros países, entre eles, Noruega, Dinamarca e Suécia. O seguro social alemão, embora apresentasse uma abrangência maior no atendimento, diferenciando-se do modelo inglês de assistência, ainda vinculava o alcance da proteção social aos que participavam do mercado de trabalho. Assim, tratava-se de um avanço, mas ainda era restrito. Importante observar que o modelo de seguro social trazia o comparativo diferencial com o caso inglês, pois os 
necessitados ingleses sofriam muito com o preconceito social por receberem "caridade". (LAVINAS; СОВО, 2009, p. 09).

Em 1942, na Inglaterra, foi apresentado o Plano Beveridge, que trazia ações destinadas à assistência da pobreza e relativas à seguro social, constituindo-se numa ação mais completa de política social. Esquemas de seguridade e tributação organizados pelo Estado protegeriam todos os cidadãos contra as cinco grandes pragas da humanidade: escassez, doença, ignorância, miséria e ociosidade (JACKSON; TANSEY, 2015, p. 98). A efetiva implantação ocorreu no ano de 1946, com a criação da Sistema Nacional de Saúde (PEREIRA, 2008, p. 112). Nesta mesma linha, o New Deal, plano que implantou uma série de medidas intervencionistas nas áreas econômica e social nos Estados Unidos (1933 a 1937), tinha na concepção a atuação do Estado como fator de proteção aos mais necessitados. Os dois planos se constituíram sob o enfoque de que o Estado deveria proteger preventivamente a população desfavorecida, garantindo recursos mínimos. Buscava-se uma cobertura obrigatória e universal, alcançando benefícios independentemente de contribuições prévias. Esta nova visão aflorou após a crise econômica de 1929 e as duas guerras mundiais (FIORI, 2012, p. 02).

O plano foi um novo marco na concepção de atendimento social, unificando a assistência e o seguro social, criando a seguridade social. A apresentação deste plano mudou a visão das políticas sociais e sua implantação é considerado o início do surgimento do Estado de Bem-Estar. A relação Estado, mercado e sociedade passou a viger sob nova forma. Inicialmente, o termo Estado de BemEstar foi empregado durante a segunda guerra mundial, para diferenciar as democracias liberais opostas aos regimes fascistas e nazistas. Após, o termo Estado de Bem-Estar se identificou com os países ocidentais em desenvolvimento que adotavam políticas sociais e econômicas visando a proteção social (LAVINAS; COBO, 2009, p. 09).

A concepção de um Estado de Bem-Estar ou Estado Social mudou a maneira de o Estado interpretar as necessidades causadas na sociedade pela pressão negativa do mercado. É o Estado identificando que não pode deixar o indivíduo a mercê dos movimentos do mercado, necessitando agir preventivamente e a posteriori, para diminuir o impacto nas vidas dos indivíduos. Ao interpretar o Estado Social, Esping-Andersen, em "As Três Economias Políticas do Welfare State", afirma que:

O welfare state não pode ser compreendido apenas em termos de direitos e garantias. Também precisamos considerar de que forma as atividades estatais se entrelaçam com o papel do mercado e da família em termos de provisão social. (ESPINGANDERSEN, 1991, p. 101)

Convencionou-se identificar o Estado de Bem-Estar ou welfare state, como o Estado que propõe intervenções no campo econômico e social através de políticas públicas de proteções sociais, com o objetivo de equalizar situações de riscos causadas pelos desequilíbrios do mercado que atingem a população. É o Estado alcançando benefícios sociais para a população sem considerar o efeito da descomodificação - Também chamado de grau de desmercantilização da força do trabalho que reflete o nível de proteção que o Estado fornece ao cidadão, garantindo condições básicas de sobre- 
vivência, independentemente de estar vinculado ao mercado de trabalho -, ou seja, independe de o indivíduo ter efetuado contribuições para programas de seguridade social.

Conforme análise efetuada, o agir do poder público no enfrentamento das crises sociais, em socorro à população menos favorecida, inicialmente produziu um atendimento através de um Estado assistencialista, onde se alcançava recursos para os necessitados para que pudessem superar o momento difícil. Posteriormente, o Estado amadureceu seu entendimento sobre os fatos que causavam desequilíbrios para certas camadas sociais e mudou sua postura passando a intervir econômica e socialmente no mercado, buscando diminuir os impactos e reequilibrar as condições de vida da população afetada. Este novo agir do poder público reflete-se ainda hoje nas políticas públicas praticadas nos principais Estados.

\section{A gestão atual da proteção social nos países europeus}

A necessidade de um sistema de proteção social tem origem nas falhas criadas pelo mercado, causadoras de incertezas e necessidades no fluxo de vida das pessoas, obrigando o Estado a realizar intervenções nas áreas social e econômica com o objetivo de criar mecanismos e condições protetivas que possam ser alcançados para a população que sofre impactos negativos no modo de vida. PIGOU (1932) ao desenvolver os princípios da economia do bem-estar identificou as falhas de mercado (monopólios e assimetrias de informações). O argumento no caso de falhas de mercado é de que o Estado pode agir para produzir melhores resultados, incrementando o bem-estar global, da sociedade. Basicamente, um sistema de proteção social deve ser direcionado para a manutenção e melhoria das condições de vida das pessoas, independentemente da situação e do tipo de risco ou crise a ser enfrentada. Na implementação das proteções sociais, o Estado precisa realizar intervenções nas áreas econômica, social e política, eis que movimentos criadores de proteções demandam atuação precisa e pontual nesses campos, objetivando criar as condições propícias para tornar os programas sociais efetivos, permitindo o acesso dos necessitados aos dispositivos públicos.

A União Europeia preocupa-se, atualmente, em identificar os níveis de pobreza e de exclusão social em que se encontram suas populações. Através da análise de indicadores como número de pessoas em risco de pobreza, níveis de grave privação material e número de pessoas que vivem em agregados familiares onde o subemprego figura com relevo (RELATÓRIO EUROPA, 2011). O relatório é realizado pelo Comitê da Proteção Social desde o ano 2000, com representantes dos EstadosMembros da união europeia em fórum permanente para discutir políticas de alto nível para reduzir a pobreza e permitir a inclusão social desta população.

Segundo o Relatório, uma em cada cinco pessoas da união europeia encontra-se em risco de pobreza ou de exclusão social, percentual que prejudica a coesão social e dificulta a solução para a saída das crises econômica e financeira. O objetivo é propor metas nacionais para cada país-membro e adotar medidas para cumprimento. $O$ trabalho objetiva que os benefícios do crescimento sejam amplamente partilhados e que as pessoas que se encontrem em situação de exclusão possam ter um papel ativo na sociedade. Para identificar a situação de risco, como medida de pobreza, a união europeia considera em risco de pobreza a pessoa que possuir rendimentos inferiores a $60 \%$ da média de seu país. É medida relativa, eis que associada com todas as fontes de rendimentos. Estes níveis 
variam conforme diferentes padrões de vida em cada país. Pelo relatório, em média $8 \%$ dos europeus sofre grave privação material e em alguns países, este índice pode chegar a $30 \%$.

O relatório preocupa-se com a qualidade da apuração dos índices de pobreza e exclusão. Para isso, analisaram um estudo realizado na Bélgica intitulado "Mini-orçamentos: qual o rendimento necessário para se viver com dignidade na Bélgica? " A finalidade era determinar uma lista de produtos e serviços considerados básicos para determinar um orçamento necessário. Os pesquisadores centraram em produtos para a saúde e para o exercício de uma vida independente. Na pesquisa, foi permitido que pessoas em risco de pobreza ou exclusão pudessem opinar sobre o orçamento. Orçamentos de referência ajudam os governos a identificar início de situações de pobreza e rendimentos das pessoas em risco.

Preocupa-se a união europeia com o nível de emprego da sua população, considerando que o desemprego é, como em qualquer lugar do mundo, o pior indicativo de início de níveis de pobreza e exclusão. Entretanto, ter emprego não é por si só garantia contra a pobreza. Conforme o relatório, $24 \%$ dos que se encontram em risco de pobreza ou exclusão estão empregados, não sendo linear o pensamento de que estando empregado estaria fora de risco. O relatório propõe atenção para a qualidade dos salários e com relação ao subemprego.

Outros fatores de inclusão social observados pelos países integrantes da união europeia dizem respeito ao nível de educação e de competências das pessoas. Conforme análise, o nível de risco de pobreza e de exclusão das pessoas poucos qualificadas é de 10 pontos percentuais superiores ao daquelas que possuem níveis médios de educação e de mais de 20 pontos percentuais superiores às pessoas altamente qualificadas (RELATÓRIO EUROPA, 2011, p. 13). É entendimento que é essencial adaptar os sistemas de proteção social de modo a fomentarem a atividade e a inclusão, através de estratégias de crescimento e níveis de trabalho melhores. A concepção dos sistemas fiscais e das prestações sociais determinam de que forma e até que limite afetam a desigualdade e ajudam os pobres.

O papel das pensões previdenciárias em vários estados-membros da união europeia é discutido. A despesa com pensões representa uma média de $43 \%$ das despesas do sistema de proteção social. O principal foco das reformas diz respeito ao reforço da ligação entre contribuições e prestações sociais, mudança na idade mínima e criação de mecanismos automáticos de correção dos benefícios, investir em saúde preventiva e acesso universal ao atendimento, atentando para o financiamento sustentável e valorização da integração dos serviços hospitalares e abordagens inovadoras na área de cuidados. Também a inclusão ativa é considerada essencial para o acesso aos benefícios e ao emprego de forma justa através de estratégias que combinem apoio financeiro adequado, acesso ao mercado de trabalho e serviços de qualidade. A cobertura da rede social deve ser melhorada assegurando o financiamento sustentável dos serviços sociais e aumentando a qualidade das intervenções.

Os chefes de estado e de governo europeus comprometeram-se a tirar da zona de pobreza e da exclusão social até 2020, pelos menos 20 milhões de pessoas. Para isto, sinalizaram com algumas medidas que devem ser seguidas: um rápido regresso ao crescimento e as políticas de emprego e de educação. Equilíbrio das finanças públicas e reformas nos sistemas de proteção social visam 
garantir a sustentabilidade e a adequação, contribuindo, assim, para preservar o papel de estabilizador automático. O Fundo Social (FSE) é o principal instrumento financeiro da união europeia para promover o emprego, a inclusão social e a igualdade de oportunidades e para desenvolver as competências e aptidões das pessoas. Outros instrumentos são o Programa Progress que apoia projetos na área de inclusão, o Instrumento de Microfinanciamento Europeu, o Fundo Europeu de Desenvolvimento Regional (FEDER) que objetiva reduzir desigualdades regionais, o Fundo Europeu Agrícola de Desenvolvimento Rural (FEADER) e o Programa-Quadro de Investigação que apoia investigação avançada socioeconômica através de novas metodologias indicadores de progresso e infraestrutura.

A conclusão do relatório é que o êxito da estratégia Europa 2020 depende de uma abordagem integrada entre todos os domínios políticos relevantes, buscando ligar os financiamentos da união europeia às prioridades da estratégia definida e apoiar a inovação social, melhorando a eficácia. Termina por observar que as políticas para lidar com as formas de pobreza e exclusão social mais persistentes e graves exigem "um conjunto de abordagens universais e direcionadas" (RELATÓRIO EUROPA, 2011, p. 18). Estas abordagens universais e direcionadas às formas de pobreza e exclusão social mais persistentes e puras identificadas no desemprego e no baixo nível da educação constituem-se num importante subsídio para a análise do estágio encontrado nas políticas sociais brasileiras.

\section{A proteção social no Brasil}

No histórico das legislações previdenciárias e trabalhistas no Brasil, identifica-se o início de um tratamento mais cuidadoso com a necessidade de proteção social para o trabalhador brasileiro, embriões de ideias de caráter social. Com a Constituição Federal de 1891, surgiu o direito de o funcionário público aposentar-se por invalidez. Em 1923, através da Lei Eloy Chaves, foi instituída a chamada CAP-Caixa de Aposentadorias e Pensões, para benefício da categoria dos ferroviários (PEREIRA, 2008, p.128). É considerada a primeira legislação previdenciária. Posteriormente, esta legislação foi estendida para os portuários e marítimos e em 1937, que havia um número considerável em todo o território nacional. O funcionamento das CAPs era autorizado pelo governo e gerenciado pelas empresas. Esta proteção previdenciária era estendida apenas para os trabalhadores urbanos. Os da área rural dependiam da assistência dos seus empregadores ou das atuações das igrejas. Na saúde, a responsabilidade era dos governos locais. Não havia programa federal. As políticas sociais possuíam caráter emergencial. Nesse período denominado laissefariano tinha-se uma política social na qual nem um mínimo de renda como provisão ínfima, era contemplado (PEREIRA, 2008, p.129).

O governo de Getúlio Vargas, a partir de 1930, iniciou o processo de industrialização no Brasil, saindo de uma aristocracia rural que dominava a cena política e econômica no país. Com as novas indústrias surgiu também uma nova e assalariada classe trabalhadora. Criou-se o Ministério do Trabalho e em 1932, e surgiu a carteira de trabalho. O governo percebeu a necessidade de regulamentar alguns direitos para estes trabalhadores, talvez não com o objetivo primeiro de protegê-los, mas sim, de dar uma nova organização para o sistema de produção. A mudança legitimava, através do apoio popular, um governo que era ditatorial. 
No período inicial do governo Vargas, havia a Lei de Segurança Nacional (1935), que impedia manifestações críticas, seja de direita ou de esquerda. Não havia espaço para que movimentos sociais de trabalhadores reivindicassem direitos. Assim, as mudanças citadas possuíam caráter centralizador, sendo originadas apenas pela vontade do governo. Não eram resultados de pressões sociais ou sindicais. Constata-se que, neste período da era Vargas, as mudanças sociais tinham objetivo político, centrado na organização do sistema produtivo. As mudanças tinham caráter conservador e mantinham as estruturas sociais vigentes.

Em 1943, o governo reuniu as legislações existentes e promulgou a CLT-Consolidação das Leis do Trabalho. O Estado legislou também em relação aos sindicatos. No entanto, isso não significou liberdade sindical e sim, um controle estatal, já que só poderia haver um sindicato por categoria e dependiam do reconhecimento do Estado para funcionar. Em 1942, a Legião Brasileira de Assistência-LBA foi criada, para atuação em nível nacional na área de assistência social, atuando em parceria com entidades filantrópicas, no auxílio de idosos e crianças. Criaram-se os primeiros Institutos de Aposentadorias e Pensões (IAP), organizados por categorias profissionais, de forma descentralizada e com apoio do Estado. O Ministério dos Negócios de Saúde e de Educação Pública centralizaram as políticas destas áreas. As ações eram centradas apenas para os trabalhadores urbanos (indústria e comércio), ficando relegados os rurais e os informais. Isso incentivava o corporativismo e gerava um clientelismo com o Estado, aumentando o poder patrimonialista do Estado. (MEDEIROS, 2001, p.12)

Do fim do Estado Novo até a "revolução" de 1964, houve um período democrático, com o aprofundamento das inovações institucionais legais ocorridas no período anterior. Novas legislações trabalhistas e previdenciárias surgiram. Na educação, surgiu a Lei de Diretrizes e Bases da Educação (1961) que expandiu o atendimento da escola pública. Apesar destas novas legislações, Draibe diz que os sistemas de proteção mantiveram um padrão "seletivo (no plano dos beneficiários), heterogêneo (no plano dos benefícios) e fragmentário (nos planos institucional e financeiro) ", (DRAIBE, 1993, p. 22). Tais características confirmam que as políticas sociais não eram universais. $O$ corporativismo no atendimento das demandas sociais manteve-se e continuou sendo política complementar no desenvolvimento industrial.

No período autoritário e com regime de exceção iniciado em 64, o Estado perdeu o aspecto populista, porém, retomou políticas sociais da era Vargas, que possuíam caráter compensatório e direcionado para o desenvolvimento industrial (PEREIRA, 2008, p.135). Com a repressão social e política, não havia condições dos trabalhadores se organizarem e pedir por melhorias. O Estado apostava no crescimento econômico como forma natural de criar avanços sociais. Assim, a política de educação foi elaborada com o sentido de qualificar os trabalhadores para aumentar a produtividade da mão de obra semiqualificada. Porém, o modelo econômico da época caracterizava-se pela concentração de renda. Segundo (Medeiros, 2001), os governos militares ao perderem o caráter populista dos governos anteriores, assumiram duas linhas distintas para as políticas sociais:

A primeira possuía caráter compensatório, constituída por políticas assistencialistas que procuravam diminuir os impactos das desigualdades provocadas pela aceleração do desenvolvimento capitalista. A segunda, de caráter produtivista, formulava 
políticas sociais visando contribuir com o processo de crescimento econômico. (MEDEIROS, 2001, p. 14)

Em 1966 criou-se o FGTS-Fundo de Garantia por Tempo de Serviço, espécie de segurodesemprego para o trabalhador. Os IAPs unificam-se com o INPS. Em 1974, dividiu-se o Ministério do Trabalho e criou-se o Ministério de Previdência e Assistência. Em 1977, criou-se o SINPAS (Sistema Nacional de Previdência e Assistência Social), englobando diversos institutos, com o objetivo de integrar a concessão, a prestação de serviços e o custeio dos segurados. Os trabalhadores domésticos, autônomos e informais continuavam excluídos do sistema de proteção. Sem democracia no período, inexistiam controles aumentando as políticas sociais clientelistas, afetando o destino de recursos e ampliação das instituições de proteção (DRAIBE, 1993, p.23).

Entre 1980 e 1985 há uma forte desarticulação social, com a diminuição de gastos sociais, acompanhada de gradual redução da importância da política social no planejamento e na gestão estatal (PEREIRA, 2008, p.147). A partir de 1985, retomou-se o processo democrático, com crescimento das atividades partidária e sindical e maior participação popular no processo político. No entanto, Medeiros (2001), anota que houve poucas inovações nos programas sociais, havendo, porém, a criação do seguro-desemprego. Em 1986, o BNH-Banco Nacional de Habitação foi liquidado. As políticas sociais tinham caráter emergencial, eis que havia falta de políticas estratégicas, creditando-se a estagnação em decorrência de crise econômica e uso eleitoreiro das políticas sociais em períodos anteriores. No entanto, nesse período, graças à mobilização da sociedade ocorreram significativos avanços que tornaram as políticas sociais centrais, na Constituição Federal de 1988.

Com a Constituição de 1988 surgiram novos direitos sociais reconhecidos como dever do Estado. Isto mudou o padrão até então corporativista do Estado Social brasileiro. Porém, não significou o alcance direto desses novos direitos para o povo. Apesar de haver eleições democráticas para os governos, as forças conservadoras mostravam-se presentes, e investiram principalmente contra as áreas da Saúde e da Previdência Social. Um dos argumentos utilizados para a não implementação de políticas sociais era a necessidade de legislação complementar regulando os novos direitos (IPEA, 2009, p. 51).

O contorno institucional do sistema previdenciário brasileiro foi definido a partir da CF/88. Desde então, passou por duas reformas constitucionais (EC 20/1988 e EC 41/2003) e regulamentações decorrentes, em especial a Lei $n^{\circ} 8213$, de 24 de julho de 1991 define e regulamenta o Plano de Benefícios da Previdência Social, e a Lei n 8742, de 7 de dezembro de 1993, Lei Orgânica da Assistência Social define que, no Brasil, a assistência social é direito do cidadão e dever do Estado (TAFNER; GIAMBIAGI, 2011, p. 114). Em 1994, surgiu o Plano Real com o objetivo de estancar a inflação e permitir o início de novo ciclo econômico. Houve abertura econômica e novos remédios na economia foram aplicados, como a valorização artificial da taxa de câmbio, e uso de reservas. O processo iniciou com alguma estabilidade na moeda e com contenções fiscais que são recorrentes, principalmente nas políticas sociais que passam por reformas. A área mais atingida foi a previdenciária, com novos institutos e regras para benefícios. Apesar da contenção fiscal, houve avanços que podem ser mencionados, como a reestruturação do sistema habitacional (SFH) e a Emenda Constitucional 
29/2000 que obriga os governos, federal, estaduais e municipais a aplicarem percentuais mínimos na manutenção do SUS.

Após a Constituição de 1988, houve mudança na trajetória histórica das políticas públicas sociais. Havia, no Brasil, um modelo seletivo e residual, o qual mudou para políticas públicas mais universalistas. Houve uma melhor definição quanto à responsabilização dos governos na aplicação das políticas públicas. A crítica em relação à mudança constitucional diz respeito ao fato de que a execução de muitos serviços públicos foi transferida para os Estados e Municípios, sem que tenha ocorrido o devido aporte de recursos para o atendimento destas competências. Esta descentralização políticoadministrativa é citada por Draibe (1993), a qual propiciaria, de maneira geral, uma maior aproximação entre demandas, demandantes e decisões no âmbito das políticas sociais. Draibe menciona, também, que vem ocorrendo, não só no Brasil, mas no mundo inteiro, uma "municipalização" do welfare state.

A marcação temporal de alguns fatos históricos, principalmente da área trabalhista, previdenciária e social, até a promulgação da atual Constituição, mostra a evolução do sistema de proteção social que o Brasil construiu.

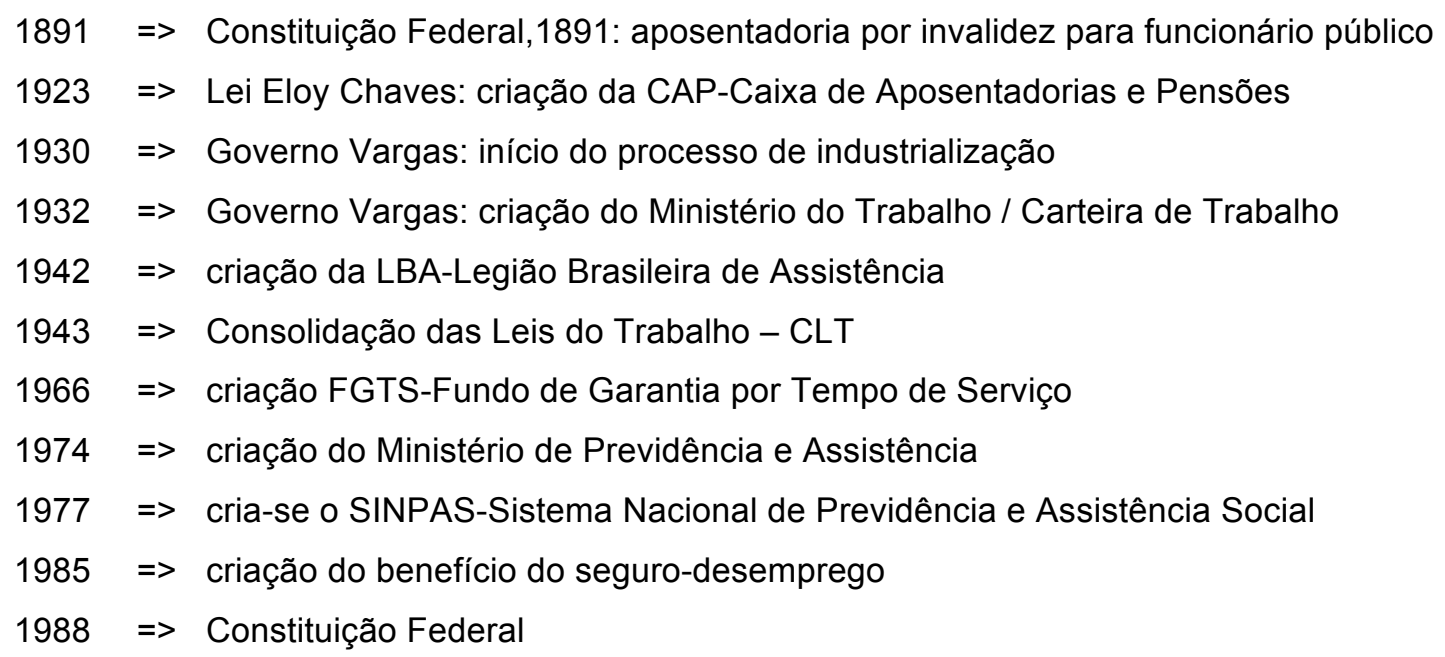

A cronologia dos fatos não indica a criação pensada de uma estrutura adequada de proteção social, mas mostram o crescimento de vários institutos relacionados com as áreas sociais. A estrutura social reflete as respostas às necessidades surgidas no caminho da consolidação da cidadania e também mostra a evolução do pensamento social. Esta evolução social está atrelada ao tipo de pensamento político adotado pelo governo no exercício do poder, o qual define as escolhas e decisões relativas às formas de prestações de serviços públicos relacionadas com os direitos sociais.

\section{Materiais e Métodos}


O trabalho inicia examinando o surgimento da ideia de o Estado amparar estes grupos da sociedade que enfrentam as consequências dos desequilíbrios social e econômico. O desenvolvimento deste conceito de prestação de serviço pelo Estado é analisado e contextualizado na época histórica, mostrando a evolução do pensamento quanto ao atendimento das políticas direcionadas para as necessidades sociais. Alguns Estados passaram a pensar e adotar políticas que contemplassem um conjunto de benefícios que pudessem ser acionados para dar um suporte econômico e social para grupos de indivíduos que estivessem passando por crises nestas áreas. O conceito de Estado de Bem-Estar Social tornou-se um objetivo a ser alcançado como referência de qualidade na aplicação de políticas públicas de proteção social.

Num segundo momento, o trabalho analisou o que pode ser considerado a implantação de algumas ideias relacionadas com a concepção de um Estado de Bem-Estar Social na sociedade brasileira. A análise observou as modificações ocorridas em legislações nos campos trabalhista e previdenciário. $O$ objetivo foi verificar se as referidas modificações possuíam caráter associado a uma nova diretriz de proteção social. As movimentações ocorreram durante o surgimento do processo de industrialização da economia brasileira, com mudança estrutural da saída de um modelo econômico e social baseado nas riquezas advindas do campo e de uma sociedade dominada pela aristocracia rural para uma economia que adentrava no nível industrial. As mudanças trouxeram exigências para o uso da nova mão de obra necessária. Paralelamente, criou-se dificuldades na vida dos indivíduos, com reflexos na visão do Estado, forçando-o a um melhor controle social no atendimento dos menos favorecidos.

$\mathrm{Na}$ parte final, o trabalho apresenta os distintos tipos de regimes de Estado, conservador, liberal ou social democrata, analisando as diferentes características que cada tipo de Estado imprime quando da execução de políticas públicas direcionadas para o atendimento de um conjunto de direitos sociais constitutivos de uma política de seguridade social. Os tipos de regimes de Estado escolhidos para a análise decorrem da interpretação do trabalho doutrinário de Esping-Andersen e do trabaIho de Donizeti Liberati em relação ao aspecto constitucional dos tipos de Estados. É realizado comparativo entre os tipos de Estado, identificando a natureza política que cada regime reflete, pois conforme a adesão que cada governo fizer, gerará reflexos diretos na escolha da estrutura do atendimento das necessidades sociais e na formatação do tipo de Estado Social que o governo oferecer para a sociedade.

O tema foi desenvolvido a partir de pesquisa teórica, com abordagem qualitativa, caracterizando-se como bibliográfica (GIL, 2016, p. 44) e utilizando-se de fontes de dados secundários. $\mathrm{O}$ estudo examina a posição de autores a respeito da concepção de um Estado de bem-estar social e do desenvolvimento de políticas sociais e suas estruturas, e com essa perspectiva busca aprimorar fundamentos teóricos e a compreensão do tema. O objetivo do trabalho foi examinar como o Estado brasileiro tem se estruturado para atender as demandas dos direitos sociais, analisando o seu nível de identificação com as bases teóricas do Estado de Bem-Estar Social. A análise observou o nível evolutivo do Estado brasileiro na execução de políticas públicas de proteção social, discutindo o tratamento dado às exigências sociais, observando o ordenamento jurídico. 


\section{Resultados e Discussão}

\section{Análise e discussão sobre os tipos de Estados de bem-estar social e o efeito político na condução das demandas sociais}

Quando um Estado implanta uma política social, ele segue padrões e critérios concebidos conforme a tendência política, econômica e social a qual está engajado. A natureza das políticas sociais aplicadas varia muito conforme os princípios e concepções político-administrativo adotados pelo governo eleito. Isto pode ser observado tanto no aspecto das qualidades das políticas alcançadas, quanto nos critérios seletivos utilizados para a concretização dos direitos sociais. $O$ trabalho apresenta as diferenças existentes em cada tipo de Estado de Bem-Estar e as variáveis identificáveis em suas políticas sociais. Na abordagem proposta por Bordieu (2014), a construção da nação como território juridicamente regulado e a construção do cidadão ligado ao Estado por um conjunto de direitos e deveres deve se prolongar numa política social, esta que define o welfare state, visando garantir a todos as condições mínimas econômicas e culturais de exercício do direito do cidadão (BORDIEU, 2014, p. 488)

As pressões decorrentes das necessidades sociais vivenciadas por parte da sociedade é que determinam o movimento governamental em estruturar um Estado de Bem-Estar. Um processo político acolhedor de participações ajuda a criar cidadãos mais eficazes e competentes, que se tornam também solucionadores de problemas mais efetivos dentro e fora do processo político (DRYZEK, 2002, p. 35). A forma como cada Estado, no exercício de sua soberania, pensa e põe em execução suas políticas sociais segue determinadas características inerentes ao pensamento político do grupo governante. Pode-se considerar que o Estado de proteção social se sustenta em três tipos de modelos, cada qual com suas características e com dinâmicas diferentes nas aplicações dos direitos sociais.

Estabelecimento de padrões nas configurações de políticas sociais: Após análise de vários welfare state, Esping-Andersen (1991), relacionou alguns padrões básicos presentes nas configurações das políticas públicas sociais, como: a forma como estas políticas são financiadas, a extensão e variedade dos serviços, o tamanho do Estado e sua estruturação. A partir destes padrões, definiu critérios mais específicos para diferenciar os tipos de Estados de Bem-Estar, como o tamanho da participação do Estado nos gastos sociais, o nível de abrangência da cobertura alcançada aos cidadãos e o grau de descomodificação da força de trabalho. Assim, Esping-Andersen restringiu em três os tipos de Estado de Bem-Estar, conforme o caráter de intervenção social do Estado.

No Estado de Bem-Estar Liberal, o auxílio não contempla a universalidade das pessoas, sendo estendido somente para àqueles que comprovem efetivamente sua condição de pobre, ficando restrita à classe trabalhadora de mais baixa renda. A quantidade de programas sociais é reduzida, com poucas transferências de renda e planos de previdência mínimos. O Estado incentiva a iniciativa privada a assumir a provisão dos benefícios estendidos aos cidadãos, com nítida mercantilização dos serviços. O liberalismo político nem aceita nem rejeita nenhuma doutrina abrangente, moral ou religiosa (RAWLS, 2003. p. 40). No regime liberal, o Estado somente participa com o auxílio quando as 
famílias não conseguem suprir suas necessidades mínimas. Em níveis mais elevados de bem-estar, a iniciativa é transferida para a área privada, através de outros tipos de seguros. São características típicas de um modelo de Estado onde o mercado de trabalho é menos regulamentado e influenciado pela ética do trabalho do sistema liberal. Pela natureza deste modelo, a característica principal é a seletividade e a pouca abrangência no alcance da assistência. Exemplos de países que utilizam este modelo liberal são os Estados Unidos, o Canadá, a Austrália. (ESPING-ANDERSEN, 1991, p. 108)

Em seu livro "Políticas Públicas no Estado Constitucional", Wilson Donizeti Liberati (2013, p. 34), analisando o aspecto constitucional, afirma que "o Estado Liberal também é chamado de Estado Liberal de Direito ou Estado de Direito. Surge, portanto, sob o signo da supremacia da lei". Liberati continua afirmando que:

O núcleo central das atividades administrativas está estreitamente submisso às normas que regulam as relações entre a Administração e os particulares e essas normas só adquirem caráter jurídico sob a égide do Estado de Direito, pressuposto (jurídico) para justificar os atos administrativos (LIBERATI, 2013, p. 34)

O Estado Liberal apresenta como características o livre funcionamento do mercado e a não intervenção do poder político em matéria econômica, social e cultural. Por tais características, é chamado também de Estado burguês, eis que identificado com os interesses da burguesia, que acabaria por manter o status quo. A democracia decorrente desse modelo permite liberdade ampla de mercado (CUNNINGHAM, 2009, p. 62). Um dos frutos do movimento liberal é a contribuição para o desenvolvimento da consciência das liberdades individuais, e a igualdade de direitos entre os cidadãos. Alguns desses direitos são reconhecidos através de previsões formais nas constituições no campo dos direitos fundamentais. Estando os direitos previstos constitucionalmente, caberia à administração pública, no Estado de Direito, observando o princípio da legalidade, concretizar os direitos subjetivos individuais. O Estado Liberal deveria promover a garantia dos direitos do cidadão através de ações administrativas públicas e universais.

O exercício da liberdade individual necessita das condições oferecidas pelo Estado para o pleno gozo dos direitos pelo cidadão Independentemente do tipo de Estado que o poder governante escolher para definir suas políticas sociais, suas ações devem ser direcionadas para a plenitude do desenvolvimento da cidadania. Amartya Sen em "Desenvolvimento como Liberdade", comenta sobre as privações de liberdade que devem ser enfrentadas para que o cidadão consiga desenvolver-se:

O desenvolvimento requer que se removam as principais fontes de privação de liberdade: pobreza e tirania, carência de oportunidades econômicas e destituição social sistemática, negligência dos serviços públicos e intolerância ou interferência excessiva de Estados repressivos. (SEN, 2000, p. 18)

Assim, na busca pelo desenvolvimento do Estado, este deveria pensar no desenvolvimento das pessoas como mecanismo para avanços econômicos e sociais. O desempenho econômico, a oportunidade social, a voz política e a argumentação racional pública estão profundamente relaciona- 
das (SEN, 2011, p. 385). Somente o Estado na concepção moderna estrutural é quem tem condições plenas e dever institucional de promover as mudanças sociais. Segundo Liberati, o Estado Liberal,

Ao descurar-se de garantir e promover atos administrativos que permitiam o exercício do direito do cidadão de realizar-se dignamente como pessoa, como, por exemplo, a universalidade do atendimento dos serviços de ensino e saúde, o Estado preocupou-se mais com permitir a produção industrial sem regras. (LIBERATI, 2013, p. 38)

Liberati complementa:

Por isto, o Estado Liberal de Direito, apesar de teoricamente observar as regras constitucionais, ficou marcado pelo completo absenteísmo do poder político em relação às estruturas econômicas, ou seja, deixou de intervir no setor econômico, permitindo que a classe industrial e produtiva agisse sem qualquer controle estatal em desprestígio da satisfação dos direitos individuais e coletivos. (LIBERATI, 2013, p. 38)

É característica do Estado Liberal a adoção de políticas sociais seletivas e a aposta no crescimento econômico como condição para melhores políticas. Desta forma, os direitos sociais não são a prioridade de atendimento para a política deste Estado. Segundo este pensamento, o Estado deve deixar o mercado evoluir, sem grandes interferências estatais, pois o foco é a liberdade do mercado, a qual acaba sobrepondo à liberdade dos indivíduos. No modelo conservador ou corporativista, os benefícios sociais estão atrelados à categoria ou setor onde o trabalhador está vinculado, restringindo, desta forma, a abrangência da assistência. A transferência de renda se dá apenas na forma horizontal, considerando que os benefícios ficam numa mesma categoria. Assim, Esping-Andersen afirma que:

Este corporativismo estava por baixo de um edifício estatal inteiramente pronto a substituir o mercado enquanto provedor de benefícios sociais; por isso a previdência privada e os benefícios ocupacionais extras desempenham realmente um papel secundário. De outra parte, a ênfase estatal na manutenção das diferenças de status significa que seu impacto em termos de redistribuição é desprezível. (ESPINGANDERSEN, 1991, p. 109)

Nesta estrutura, o impacto das políticas sociais acaba sendo pequeno, uma vez que os benefícios acabam estendidos para quem possui vínculo empregatício, o que exclui os mais carentes de proteção. Neste modelo, a desmercantilização do Bem-Estar é maior do que no modelo liberal. O Estado, ao validar o modelo conservador e preservando estas diferenças, contribui para que não ocorra redistribuição de renda, considerando que a linha política não permite avanços fora da proposta apresentada pelo poder público. O modelo conservador é praticado, com algumas variáveis, em países como França, Áustria, Alemanha, Itália (PEREIRA, 2011, p. 191). 
Ao tratar da liberdade como um instrumento para o desenvolvimento social, Amartya Sen (2000, p. 24) afirma: "O exercício da liberdade é mediado por valores que, porém, por sua vez, são influenciados por discussões públicas e interações sociais, que são, elas próprias, influenciadas pelas liberdades de participação". O instituto da liberdade precisa amparar-se em determinados valores, os quais darão consistência ao exercício da liberdade para efetivamente poder ser um mecanismo de desenvolvimento. Naturalmente que estes valores precisam ser encontrados através de condições propiciadas pelo próprio Estado. No entanto, ao considerar que este modelo de Estado adota o conservadorismo como linha política, econômica e social de atuação, o mesmo não se apresenta como melhor opção de desenvolvimento social.

No Estado de Bem-Estar Social Democrata, existe a preocupação com a universalização da proteção aos necessitados. Defende-se o pensamento de que o Estado deve agir para estender benefícios sociais para todas as classes sociais, independentemente de classe ou categoria, criando desta forma o princípio da igualdade e tendo nos programas sociais a característica da desmercantilização. Há a ideia de alcançar benefícios em padrões maiores do que a simples necessidade mínima. E também a de que o atendimento das necessidades de proteção das pessoas deve ser preventivo, não esperando as crises acontecerem. Este regime preconiza que o Estado assuma a responsabilidade pela proteção social em conjunto com as famílias. O modelo social democrata tem comprometimento com o pleno emprego. Há incentivo para que as pessoas assistidas obtenham a autonomia, que as mulheres retornem ao mercado de trabalho. Com isso, tornam-se produtivas e mais participantes da sociedade, diferenciando-se assim do modelo conservador. A emancipação do ciclo de proteção social contribui, inclusive, para o recolhimento de impostos, ajudando a manter este tipo de regime. O modelo social democrata pode ser considerado o tipo mais puro de Estado de Bem-Estar Social. É praticado em países como a Suécia, Noruega, Finlândia.

A questão social como essência de modelo político começa a se caracterizar pela ocorrência de determinadas situações. Segundo Liberati,

Originalmente, a questão social foi constituída em torno das transformações econômicas, políticas e sociais ocorridas na Europa do século XIX, devidas à industrialização, ao crescimento demográfico, à urbanização e ao fracasso político do liberalismo econômico puro. Traduz-se não na concepção de Estado (inclusive em nível constitucional), mas nas medidas legislativas concretas de corte social, formuladas em relação com específicas situações de graves e urgentes necessidades (sobretudo nos casos relacionados à seguridade social frente às situações de enfermidade e acidentes de trabalho), (LIBERATI, 2013, p. 45)

Analisando o aspecto constitucional da formação do Estado Social, em relação à origem de sua legitimação, Liberati afirma:

O Estado Social, por sua própria natureza, demanda a participação popular, o que significa que o Estado Social é, também, um Estado Democrático, tem, no povo, a origem do poder político e que se funda na legalidade. Ou seja, um Estado Social Democrático. (LIBERATI, 2013, p. 45) 
Ao Estado Social cabe fazer as intervenções necessárias para correções dos problemas causados pela pressão do movimento dos mercados. Estas intervenções devem direcionar-se, primeiramente, para as principais áreas afetadas e que podem trazer novamente o equilíbrio social e econômico. No entanto, estas são ações emergenciais a serem enfrentadas, diferentemente da política social qualificada que deve estar embasada em programas estruturados e bem planejados para que possam efetivamente produzir a mudança protetiva social duradoura e alinhada com a busca pelo desenvolvimento. Mas quando se fala em intervenções, não se pode simplesmente ignorar a força do mercado. Amartya Sen, afirma:

É difícil pensar que qualquer processo de desenvolvimento substancial possa prescindir do uso muito amplo de mercados, mas isso não exclui o papel do custeio social, da regulamentação pública ou da boa condução dos negócios do Estado quando eles podem enriquecer - ao invés de empobrecer - a vida humana. (SEN, 2000, 22, p. 22)

Analisando o Estado Social em relação aos seus fins, Liberati afirma:

Pode-se afirmar que os fins desejados pelo Estado Social - marco histórico do Estado Democrático e de Direito - são a defesa da igualdade e da liberdade do homem. Neste sentido, a atividade estatal de prestação de serviços públicos dirige-se à satisfação do bem-estar do ser humano em seu meio ambiente e atendendo às suas necessidades. (LIBERATI, 2013, p. 46)

Esping-Andersen, analisando o Estado Social Democrata adota a seguinte posição:

Em vez de tolerar um dualismo entre Estado e mercado, entre a classe trabalhadora e a classe média, os social-democratas buscaram um welfare state que promovesse a igualdade com os melhores padrões de qualidade, e não uma igualdade das necessidades mínimas, como se procurou realizar em toda a parte. (ESPINGANDERSEN, 1991, 109, p. 109)

E, ao analisar a diferença do modelo social democrata em relação ao modelo conservador quanto ao processo emancipatório dos beneficiados, fez a seguinte observação:

A política de emancipação do regime social-democrata dirige-se tanto ao mercado quanto à família tradicional. Ao contrário do modelo corporativista-subsidiador, o princípio aqui não é esperar até que a capacidade de ajuda da família se exaura, mas sim de socializar antecipadamente os custos da família. O ideal não é maximizar a dependência da família, mas capacitar a independência individual. (ESPINGANDERSEN, 1991, p. 110)

E complementa, ao falar sobre a principal característica do modelo social democrata: 
Talvez a característica mais notável do regime social-democrata seja a fusão entre serviço social e trabalho. Está ao mesmo tempo genuinamente comprometido com a garantia do pleno emprego e inteiramente dependente de sua concretização. Por um lado, o direito ao trabalho tem o mesmo status que o direito de proteção à renda. De outra parte, os enormes custos de manutenção de um sistema de bem-estar solidário, universalista e desmercadorizante indicam que é preciso minimizar os problemas sociais e maximizar os rendimentos. A melhor forma de conseguir isso é, obviamente, com o maior número possível de pessoas trabalhando e com o mínimo possível vivendo de transferências sociais. (ESPING-ANDERSEN, 1991, p. 110)

O tipo de Estado de Bem-Estar Social está atrelado a ideias, interesses e forças políticas dominantes na sociedade nas distintas etapas de emergência, desenvolvimento e mudanças dos sistemas nacionais de proteção (DRAIBE, 2014, p. 36). A diretriz a ser seguida para a política social, fator essencial para a definição do tipo de Estado Social, dependerá das escolhas políticas. Adotada determinada linha social, molda-se a apresentação da política pública e cria-se os mecanismos estruturantes para sua efetivação. O modelo adotado refletirá nas estruturas sociais do Estado.

\section{O modelo brasileiro e as estruturas de Estado}

Qual seria a identificação do modelo brasileiro? As primeiras políticas sociais no Estado brasileiro iniciaram com o objetivo de legitimar um governo. Assim foi feito através das publicações das legislações trabalhistas na década de 30, no governo de Getúlio Vargas, apostando no controle dos trabalhadores para impulsionar o sistema produtivo industrial (BRESSER, 2015, p. 126). Num outro momento, no regime militar pós 64 , o plano educacional do ensino público foi direcionado para a formação nas áreas técnicas para produzir trabalhadores para a necessidade industrial do país. A Carta de 1967 silenciou sobre a vinculação de recursos para o financiamento da educação (NUNES, 2016, p.54). Com a CF/1988 surgem avanços nas políticas públicas, com a criação de instituições com o objetivo de universalizar as políticas sociais.

Inicialmente, o Estado brasileiro pode ser enquadrado na tipologia de Estado de Bem-Estar Social definido por Esping-Andersen, relacionado com o modelo de regime conservador ou corporativista. Neste regime, as políticas sociais são seletivas, diferentes conforme as classes. Este tipo de atuação acaba por não redistribuir renda na sociedade. As características do corporativismo apresentam-se sob várias formas, como por exemplo, na área trabalhista, os avanços não eram universais, havia exclusões dos trabalhadores da área rural e dos domésticos. A própria criação do FGTS surgiu em supressão ao direito de estabilidade que o trabalhador possuía (CARVALHO, 2014, p. 172). Na mediação de conflitos, o Estado trazia a responsabilidade para si, considerando o controle que exercia sobre os sindicatos. No campo previdenciário, o objetivo era conceder, ao trabalhador, benefícios equivalentes aos valores contribuídos; no entanto, pelos problemas de sustentabilidade do sistema, não houve cumprimento dessa diretriz. Por outro lado, a concessão de benefício somente para àqueles que tenham contribuído, também é sinal de atuação conservadora. A manutenção das estruturas sociais caracteriza este regime. 
A estruturação do Estado na prestação de serviços sociais começou a mudar com a CF/1988. Ela trouxe um olhar diferente para a área da seguridade social, com a criação de institutos sociais. $\mathrm{A}$ ideia do acesso universal é considerada um avanço no campo dos direitos sociais. $\mathrm{Na}$ área da saúde, a criação do SUS - Sistema Único de Saúde, garantindo a todas as pessoas atendimento independentemente de pagamento de contribuições é avanço universal na prestação de serviço público. Porém, a demora na aprovação de leis complementares de regulamentação acabou gerando a dificuldade na aplicação dos direitos e criou um processo clientelista bastante utilizado em épocas eleitorais. Apesar da oferta de uma cobertura universal, desigualdades na utilização de serviços de saúde relacionadas à renda são persistentes, sendo ampliadas pelas desigualdades regionais na distribuição de renda (CAMBOTA; ROCHA, 2016, p. 290). Vale referir que a saúde não conseguiu manter a qualidade no atendimento permitindo que a iniciativa privada explorasse a área, transformando-a num excelente campo de negócio. Isto caracteriza o Estado conservador.

É interessante observar que a característica da universalização, por si só, não é garantia de identificação do Estado em regime não conservador. O caso da educação é sintomático. Em várias Constituições, constou como um direito de todos, independentemente de pagamento. Inicialmente era centralizada na União, com competências distribuídas posteriormente para os Estados e Municípios. Ocorre que a participação intensa da área privada no ensino superior e em menor grau no ensino médio, configuram características de um Estado de Bem-Estar Social tipo conservador. No campo habitacional, o Estado brasileiro também não possui um bom histórico, eis que somente na década de 70 é que se fala em política habitacional. O SFH-Sistema Financeiro de Habitação foi criado com várias instituições que se destinavam a captar recursos para a construção de imóveis residenciais. Parte deveria ser destinada para as populações de baixa renda. Este processo não ocorreu da forma como deveria, fugindo do caráter redistributivo. Somente na década de 90 com a criação dos programas da Carta de Crédito-FGTS e Habitar Brasil e Pró-Moradia houve melhora no processo de redistribuição de renda habitacional.

A Constituição de 1988 trouxe grandes inovações na área social e avanços em direitos e garantias relacionados com os direitos sociais, influenciando uma nova estrutura social com participação do Estado mais efetiva e com caráter universalista. A Constituição veio confirmar direitos conquistados pela sociedade que passaram a ser reconhecidos através de previsões normativas. Os acessos aos serviços como, saúde, educação, assistência social atingiram um número maior de pessoas com uma cobertura melhor destas políticas sociais. $\mathrm{Na}$ área da assistência social, houve um considerável aumento nos valores do gasto público. Registra-se que o tamanho deste gasto sempre esteve atrelado ao bom desempenho econômico. Mas, contraditoriamente, não houve o mesmo gasto público nas áreas de saúde e educação, devido às restrições orçamentárias. Os acessos à saúde, educação e assistência social passaram a ser um direito universal, independentemente de o cidadão estar empregado (descodificação) diferente do modelo anterior que vinculava o acesso do indivíduo ao mercado formal de trabalho.

Quanto à previdência, outra área sensível em estruturas de bem-estar social, houve melhorias com a inclusão de trabalhadores da área rural, melhorando a equiparação com os urbanos. Conforme o Relatório do IPEA-Políticas Sociais: acompanhamento e análise: 
O sistema de previdência brasileiro tem importante papel na garantia de renda dos trabalhadores ativos e inativos, sobretudo o Regime Geral de Previdência Social (RGPS), que abarca, em sua maioria, os trabalhadores da iniciativa privada. Graças à sua crescente cobertura, aliada à vinculação do piso do salário mínimo (SM) e aos diversos esquemas de solidariedade entre as categorias de trabalhadores cobertos, o sistema tem tido impactos muito positivos sobre a pobreza, a desigualdade e o crescimento econômico nos últimos anos. Ademais, logrou-se tal efetividade reduzindo-se o custo de seu financiamento em relação ao produto interno bruto (PIB). (IPEA, 2011, p. 15)

Porém, a previdência continuou tendo característica de seguro e de vinculação ao mercado de trabalho, com exigência de contribuição para obtenção de aposentadorias ou seguros diversos, já existentes antes da Constituição. Nos últimos governos, a realçar o fator distributivo de renda, através da política de reajuste do salário-mínimo com índices acima da inflação, se permitiu, aos segurados, um ganho real em seus benefícios. A estabilidade dos indicadores de cobertura também é fator positivo. Dentre os desafios que o Relatório do IPEA (2011, p. 07) apresenta para a melhoria da função social previdenciária, cita-se: o aumento da justiça distributiva do sistema, a elevação da cobertura dos trabalhadores ativos e a necessidade de redefinição de parâmetros para a concessão de aposentadorias, devido às mudanças demográficas em curso (projeções populacionais).

Observa-se no histórico brasileiro que o Estado sofre com as constantes mudanças nas estruturas para a prestação dos serviços, com extinção ou modificação das mesmas, sempre a reboque da política do momento. Em qualquer época analisada, o componente político será sempre foi fator decisivo no avanço ou retrocesso das implementações e execuções das políticas públicas, considerando a força que as decisões políticas imprimem às ações.

\section{Conclusão}

O estudo mostra o histórico da evolução do que se considerou chamar de Estado de BemEstar Social, identificando que o Estado brasileiro nunca teve uma política de proteção social realmente pensada, estruturada com base em instituições públicas constantes e seguras. A evolução das instituições prestadoras de bens e serviços públicos ocorreu com sobressaltos históricos e necessidades pontuais de um Estado mais preocupado em manter o status quo e controlar demandas de trabalhadores e de sindicatos, incentivando processos de produção econômica. O Estado brasileiro não mantém estruturas e instituições públicas consistentes, faltando organização em todos os níveis, impedindo a oferta de bens e serviços públicos de qualidade à sua população. Isso decorre do próprio processo evolutivo democrático do país e das mudanças nas ações políticas que geraram opções de políticas públicas diferentes, impedindo uma necessária continuidade de estruturas e instituições. Esta condição colaborou para a direção que o Estado brasileiro tomou, para um ou outro tipo de regime de Bem-Estar. 
Ao Estado brasileiro quando da execução de qualquer política social, cabe atentar para objetivos primordiais na oferta de políticas públicas, especificamente quanto à necessidade da utilização dos benefícios sociais e de que forma o cidadão liberta-se desses benefícios. Nessa linha, o primeiro atendimento do Estado Social deve ser atender as necessidades de assistência social. Num segundo movimento, o Estado deve trabalhar para promover a inclusão das pessoas que se encontram em situações de riscos sociais e/ou econômicos e, no terceiro e último estágio, como consequência da assistência e da inclusão alcançada, surge a necessidade de o Estado proporcionar para as pessoas que usufruíram dos benefícios, possibilidades de as mesmas alcançarem as autonomias necessárias para atingirem um nível emancipatório dessas políticas sociais. O sucesso das políticas sociais de qualquer governo deve ser medido pela capacidade de os Estados proporcionarem aos demandantes dessas políticas públicas, a possibilidade de obterem a completa independência das mesmas.

Considerando a Constituição/88 como um referencial de mudanças, pode-se identificar que a partir de então, o Estado brasileiro começou a deixar para trás o modelo conservador e corporativista, aproximando-se do tipo de Estado de Bem-Estar Socialdemocrata, apesar das fragilidades das instituições, do modelo político praticado e das opções econômicas adotadas. O tema é vivaz, permitindo novos estudos sobre esta ou outras análises.

\section{Referências}

BORDIEU, P. Sobre o Estado: cursos no Collège de France (1989-92). Tradução Rosa Freire d'Aguiar. São Paulo: Companhia das Letras, 2014.

BRESSER- PEREIRA, L. C. A construção política do Brasil. São Paulo: Editora 34, 2015.

CAMBOTA, J. N.; ROCHA, F. Evolução das Desigualdades Sociais na Utilização de Serviços de Saúde: análise para as regiões e as unidades da federação do Brasil. IPEA, Revista Eletrônica Planejamento e Políticas Públicas, n. 46, jan./jun. 2016.

CARVALHO, J. M. de. Cidadania no Brasil: o longo caminho. Rio de Janeiro: Civilização Brasileira, 2014.

CONSTITUIÇÃO FEDERAL DO BRASIL. 1988. Disponível em < http://www4.planalto.gov.br/legislacao >Acesso em 14 maio 2017.

CUNNINGHAM, F. Teorias da Democracia: uma introdução crítica. Tradução Delmar José Volpato Dutra. Porto Alegre: Artmed, 2009.

DRAIBE, S. M.O Welfare State no Brasil: características e perspectivas. Caderno $\mathbf{n}^{\circ} \mathbf{0 8}$, NEPP, Unicamp, Campinas, 1993.

Estado de Bem-Estar, Desenvolvimento Econômico e cidadania: algumas lições da literatura contemporânea. In: HOCHMAN, Gilberto; ARRETCHE, Marta; MARQUES, Eduardo (Org.) Políticas Públicas no Brasil. Rio de Janeiro: Editora Fiocruz, 2014.

DRYZEK, J. S. A post-positivist-analytic travelogue in the good society, v 11, n. 1, 2002.

ESPING-ANDERSEN, G. As Três Economias Políticas do Welfare State. Revista Lua Nova, n. 24, setembro, 1991. 
EUROPA. A Dimensão Social da Estratégia Europa 2020. Um Relatório do Comitê da Proteção Social, 2011.

FIORI, J. L. Estado de Bem-Estar Social: padrões e crises. Última modificação 10/12/2012. Disponível em: < www.iea.usp.br/artigos >Acesso em 29 set. 2014.

GIL, A.C. Como elaborar projetos de pesquisa. São Paulo: Atlas, 2016.

IPEA. Políticas Sociais: acompanhamento e análise: vinte anos da Constituição Federal. Brasília, 2009.

JACKSON, N. A.; TANSEY, S. D. Política. Tradução de Marcel Gugoni e Leonardo Abramowics. São Paulo: Saraiva, 2015.

LAVINAS, L.; COBO, B. O Direito à Proteção Social: perspectivas comparadas. Dezembro de 2009. Disponível em < http: //library.fes.de/pdf-files/bueros/brasilien/07114.pdf > Acesso em 26 set. 2014.

LIBERATI, W. D. Políticas Públicas no Estado Constitucional. São Paulo: Atlas, 2013.

MEDEIROS, M. A trajetória do Welfare State no Brasil: papel redistributivo das políticas sociais nos anos 1930 aos anos 1990. Brasília: IPEA, 2001. (Texto para discussão n. 852).

NUNES, A. N. F. Financiamento da educação básica no Brasil: uma análise dos arranjos jurídicos adotados ao longo do período republicano. Revista Digital de Direito Administrativo da USP, v. 4, n. 1, 2017.

PEREIRA, P. A.P. Necessidades Humanas: subsídios à crítica dos mínimos sociais. São Paulo: Cortez, 2008.

PEREIRA, P. A.P. Política Social: temas \& questões. São Paulo: Cortez, 2011.

POLANYI, Karl. A grande transformação. As origens da nossa época, Rio de Janeiro: Campus, 1980.

PIGOU, A. C. The Economics of Welfare. 4 ed. Londres: Macmillan, 1932. Disponível em http://www.econlib.org/library/NPDBooks/Pigou/pgEW32.html\#Part II, Chapter 21. Acesso em 18 nov.2017.

RAWLS, J. Justiça como equidade: uma reformulação. Tradução Claudia Berliner. São Paulo: Martins Fontes, 2003.

SEN, A. Desenvolvimento como Liberdade. São Paulo: Companhia das Letras, 2000.

TAFNER, P.; GIAMBIAGI, F. Previdência Social: uma agenda de reformas in Brasil: a nova agenda social. Rio de Janeiro: LTC, 2011. 